\title{
$\bullet$ Asthma Simulation Team Experience Using Hybrid Modeling
}

\section{IJCRR}

Section: Healthcare

Sci. Journal Impact

Factor: 6.1 (2018)

ICV: 90.90 (2018)

(c) (7) (3)

Copyright@IJCRR

\section{Younsook Ju' ${ }^{1}$, Muyeong Seak Yang ${ }^{2}$}

'Assistant Professor, Department of Nursing, Hanil University, South Korea; 'Associate Professor, Department of Nursing, Jesus University, South Korea.

\section{ABSTRACT}

This study attempted to learn about students' experiences as they encounter problems in the team-based simulation learning process, specifically when they interact with asthmatic patients during clinical trials involving hybrid model methods, asthma standardized patients, and human patient simulators.

Aim and Scope: Thus, in this study, nursing students had the opportunity to experience a theoretical knowledge of asthma and direct nursing for patients with diseases through team-based learning courses.

Method: The team-based simulation learning method using these hybrid models is believed to be a useful foundation for improving students' knowledge, interacting with colleagues, and confidence in practice.

Conclusion: It is judged that the team is engaged in clinical practice with the process of expanding the thinking and human relationships, and self-examination, while engaging in the learning experience of the team for simulation of asthma patients.

Key Words: Students nurses, Simulation team learning experiences, Clinical experience.

\section{INTRODUCTION}

Nursing education has recently been studying various practical training methods to enhance field practice and to achieve core skills in each field of practice. ${ }^{1,2}$

Since nursing students acquire theoretical knowledge and adaptive skills related to technical attitudes through clinical practice training, clinical practice education is important to have practical nursing skills.

However, for nursing students to acquire practical nursing skills in the current clinical practice environment, there are difficulties such as lack of communication opportunities with medical staff, patients and caregivers, refusal of patients to perform nursing care, students' immature nursing performance, and more advanced clinical practice than theoretically learned, so there is a lack of practical nursing opportunities, ${ }^{3,4}$ which can be performed directly by nursing care students, and the observation of direct nursing intervention is underway. ${ }^{5,6}$

It has become difficult for nursing students to acquire the core competency of nursing at clinical sites. Compared to the past, as the human rights and safety of patients in clinical practice have been strengthened, the scope of practical practice of nursing students has been limited to integrating and applying theoretical knowledge to working sites throughout educational opportunities. Students' nursing practice in clinical sites been conducted through hands-on practice and passive practice, excluding simple tricks such as vital signs measurement.

As a result, the nursing education community is making effort to improving clinical practice education, especially since students are exposed to a clinical practice environment where they are not able to perform their role as the original practical training centre. In turn, nursing students are not able to train their practical nursing skills, making it difficult to achieve their goals in practical training. ${ }^{7}$ Simulations are used in nursing education to solve these problems of clinical practice education and to create a clinical-like environment at the nursing education site so that nursing students can actively learn basic knowledge and practical skills.

\section{Corresponding Author:}

Younsook Ju, Assistant Professor, Department of Nursing, Hanil University, South Korea; Email: Angelqueen@hanil.ac.kr

ISSN: 2231-2196 (Print) ISSN: 0975-5241 (Online)

Received: 07.07.2020

Revised: 10.08 .2020

Accepted: 12.09 .2020 Published: 06.10 .2020 
Simulation training is a course designed to mimic real-life situations and is reported to have a positive effect on improving nursing students' self-efficacy, academic performance, and satisfaction by providing a safe learning environment that is useful in acquiring practical skills, including essential basic nursing skills, using computerized patient simulators, models, scenarios, and standardized patients on behalf of actual patients. ${ }^{8,9,10}$

Simulation training can be classified by using a low-fidelity simulator in High Fidelity, in which a standardized patient plays the role of an actual trained patient and also by using a hybrid method that uses a simulator and a standardized patient together. Simulation training classification depends on the simulator performance used to describe the actual clinical situation.

Among them, professors can choose and operate the education methods they want. Hybrid methods, also known as the Integrated Performance Instrument (IPPI) for standardized patients and models, have been increasingly used in medical education in recent years because they are valuable in that they can not only imitate a real scenario but also implement important procedures that can occur in real-world situations. ${ }^{11}$

Standardized patients, for example, can perform health and nursing interventions while acting and communicating like real patients with professional training. Also, various symptoms that may appear to the target during the health assessment can be simulated using a hybrid method that allows the model student to perform nursing. These methods of education are reported to improve students' nursing performance, communication skills, problem-solving skills, and learning satisfaction, ${ }^{13}$ and are expected to help nursing students with clinical stress as they communicate with the subjects in situations similar to real situations, away from the practice of alcoholism. The Korean Institute of Nursing Education (KABONE) also recognized up to $10 \%$ of clinical practice time as the simulated practice in the second-cycle certification evaluation criteria. The simulation-based education is gradually and continually increasing as seen in the third certification assessment, where up to $15 \%$ of clinical practice time is simulated practice. Simulation training promotes critical thinking through the debriefing phase, which analyzes what learners and educators felt in implementing scenarios or whether they are suitable for the applied nursing process and key periods, and improves their knowledge of communication and clinical performance. ${ }^{14}$

Simulation training can be done individually or as a team and is most effective when there are no more than 10 people. ${ }^{15}$ In simulation practical training, which is being used in various ways to improve nursing practical skills, the learner's basic operating structure is operated as a team, not as an individual. ${ }^{16}$
Team-based learning is reported to be able to enhance nursing students' problem-solving skills, interpersonal formation skills, and academic achievement. They can experience the thinking process of integrating, applying, and evaluating knowledge through active interaction of team members in problematic situations that can occur in clinical trials. ${ }^{17,18}$

The team-based simulation learning method focuses on allowing nursing students to solve problems through team activities by themselves, away from the professor-centred learning method. This method of learning requires nursing students to change from passive to active learning attitude, which requires a deep exploration of how nursing students, who are the subjects and subjects of learning, accept, experience, and solve the new learning method of team-based simulation learning.

Through many studies, the main methods of education used in nursing education team-based learning include simulation training using human patient simulators (HPS) and simulation training using standardized patients (SP). Although there is a limit to what HPS can realize, the use of well-trained SP patients can more realistically implement the symptoms of patients that can be encountered in a truly unstructured learning environment. ${ }^{19}$ Team learning allows team members to practice their roles, study each other's actual patients, and implement various emotions and clinical symptoms that the target can feel as if they are real. Students in clinical practice are stressed in responding to the needs of the subject in unpredictable clinical settings, ${ }^{20}$ and experience a loss of selfesteem and a burden in the course of the exercise. ${ }^{21}$

In particular, students are under high pressure to take care of patients safely with confidence, as they are subject to severe appeals and rapid response, such as difficulty breathing, ${ }^{22}$ so it is important to practice simulations in a clinically similar environment. ${ }^{23}$ As part of the repetitive exercise, each team was composed of 4-5 people, and each team was required to establish the following scenario. First, each team set up a patient with asthma standardization with the same symptoms they had experienced during adult clinical nursing practice. Then they set up roles for each team. Studies have shown that scenarios contribute to improving the clinical judgment ability of nursing students by making them think and choosing appropriate arbitration to link simulation experience with practical clinical experience in the lab. ${ }^{24}$ The results of tests not being implemented by standardized patients were used by human patient simulators (HPS). The scenario of the students based on the team was examined by two adult nursing professors and two male nurses who have been working in respiratory medicine for more than 10 years. This study attempted to understand in-depth the specific and vivid educational experience of third-grade nursing students who experienced clinical conditions by utilizing asthma standardized patients and human patient simulators and to find out how it works for nursing students to learn about the team. 


\section{Design Method}

\section{Research Design and Research Methods}

The design of the study is a qualitative study to identify the basic data of asthma simulated patient team learning experience and to find cultural specificity, applying cultural technical journals and qualitative methods such as interviews and observations.

Field research techniques are used, and field research enters the everyday scene where human behaviour occurs, and participant observation and interview are the main methods.

\section{Selection of research participants and ethical consid- erations}

A total of 11 third-year nursing students from W County, North Jeolla Province, are eligible for the study. The purpose of the study was explained and students who wanted to participate in the study were selected as participants in the study. For ethical consideration of study participants, the purpose and procedures of this study were explained before the study was started, and after explaining that no guarantee of anonymity or interviews would be used for any purpose other than research, the participants' participation observations and interviews were directly explained and agreed to be treated anonymously.

\section{Data Collection}

The data collection period is four weeks from September 21,2016 , to October 19, 2016, when the data reached saturation, and participants in the study took courses related to adult nursing, respiratory system disorder, and selected 11 students willing to participate in the study from among the third-year students of the department of four-year nursing who had clinical practice experience in the respiratory tract ward. The recruitment began shortly after the clinical practice was completed, and after the simulation class, the participants' consent was obtained and recorded. Also, to ensure participants' confidentiality, the computer was given a number that only researchers knew, removing information related to the participants.

In-depth face-to-face talks were conducted one or two times, and the first face-to-face talks took about an hour, and the second face-to-face talks were held for about 60 minutes, focusing on the unclear parts of the first face-toface talk or the lack of statements from participants. Also, the interview was conducted in the researcher's laboratory at a convenient time for participants, and the tape recording the participant's statement was translated into writing on the same day and used as analysis data, and the recorded data was deleted.

\section{Data Analysis}

Two nursing PhDs with experience in qualitative research participated in the data analysis process to ensure that the categorized content, the contents of the related areas, were consistent with the raw materials, and to reduce errors in the researchers' unilateral thoughts or preconceptions and judgements, and to increase reliability. One Korean literature major joined the naming process and discussed and named it together, and finally, one doctor of nursing was consulted and evaluated.

\section{RESULTS OF RESEARCH}

\section{General characteristics of the subject}

The age distribution of those subject to this study was 23 to 24 years old, and the average age was 23.09 years old. There were a total of 11 third graders, one male student and 10 female students, seven Christians in religion and four nonreligious people. All 11 were unmarried. Six people were living alone and five people living in their homes. Seven students applied for the department voluntarily, and four students were admitted to nursing colleges on recommendation and recommendation.

\section{Results based on the characteristics of the subject}

The qualitative research analysis on the asthma simulation team's learning experience using the hybrid model method resulted in a total of 54 raw materials, 10 components, 6 categories, and 4 areas ( Table 1). The four areas were derived from lack of knowledge, human relations, critical thinking, and confidence.

Table 1: The qualitative research analysis on the asthma simulation team's learning experience

$\begin{array}{lll}\text { S. No } & \text { Area } & \text { Category and Components } \\ & \text { Lack of } & \text { "Trying to write a scenario has allowed } \\ & \text { Knowledge } & \text { me to learn about a disease I don't } \\ & \text { know." (\#5) } \\ & \text { "By applying the nursing process, we } \\ & \text { were able to find out the rationale we } \\ & \text { did not know about each technique." } \\ & \text { (\#6) } \\ & \text { "I was able to learn more about the dis- } \\ & \text { ease by writing the scenario, and it was } \\ & \text { good to correct the key tricks that I had } \\ & \text { never known before through simula- } \\ & \text { tion." (\#3) } \\ \text { Extending } & \text { "We became close to the group mem- } \\ \text { Human } & \text { bers while doing our group project, and } \\ \text { Relations } & \text { it was important to understand each } \\ & \text { other's tendencies." (\#7) } \\ & \text { "We felt the importance of harmony } \\ & \text { and communication with each other at } \\ & \text { the nursing site" (\#9) } \\ & \text { "It was a useful time to ask questions to } \\ & \text { each other and help each other" (\#3) }\end{array}$




\section{Table 1: (Continued)}

$\begin{array}{ll}\text { S. No } & \text { Area } \\ 3 & \text { Critical } \\ & \text { Thinking }\end{array}$

Category and Components

"I think having time for debriefing has allowed me to think differently and feel better while looking at the other group." (\#9)

"I was able to learn what I didn't think through the other group." (\#10)

"It was beneficial to be compared and discussed with images from other groups" (\#1)

Increase

"Thinking, understanding, caring, confidence etc. have improved further and I have gained confidence" (\#3)

"I could feel confident and fulfilling by doing a hands-on exercise through my scenario" (\#11)

"Theoretical knowledge has also been acquired and confidence has grown in the practical practice department." (\#2)

\section{DISCUSSION}

Through interviews and observations on the learning experience of asthma simulation team using hybrid model methods, this study provided data to assist students in qualitative simulation and tried to find their cultural specificity. The significance of this study was attempting to identify the experiences of nursing students through team learning as well as through nursing interventions for similar nursing subjects. These similar subjects were matched in clinical practice following team-based simulation, based on their experiences related to knowledge, human relationships, critical thinking, and confidence experienced in the simulation team learning experience.

The team-based simulation class was run for a team of 4-5 members over a total of three weeks, one week of orientation training for each team, one week of practice according to scenario conditions, and one week of evaluation through the hybrid model method.

Through in-depth interviews, experiences related to lack of knowledge, expansion of human relations, critical thinking, and self-confidence were derived.

Before the simulator practice began, the researcher minimized his resistance to the human simulator by allowing him to experience not only abnormal pulmonary sounds but also wheezing sounds, vital signs and deep sounds, which are available responses in the human simulator. However, some students have already learned from the theory and experienced a lack of theoretical knowledge about asthma patients and various nursing seasons for acute asthma patients in clinical trials, even though they had the opportunity to meet the asthma target through practice. Through this experience, theoretical knowledge has been deeply accumulated and the team itself has learned the importance of their respective roles to solve problems. This experience is also shown in other studies, in which students compare the level of learning or knowledge of themselves or their peers during the debriefing session, and discover their strengths and weaknesses and inspire a sense of competition and desire to learn, allowing them to identify their shortcomings. Another study said that they experienced an improvement in clinical knowledge levels. ${ }^{25}$ Students were able to awaken interest in nursing knowledge through team-based simulation learning methods, and they recognized the difference between theory and practice and learned the practical application method so that it was remembered longer than simply memorized memorization. So the more knowledge and practice the more positive the learner's attitude, ${ }^{25}$ and if the professor develops a learning enzyme that can provide nursing students with sufficient learning opportunities and promote team activities, the competence of nursing students may increase. ${ }^{25}$

Nursing students said they experienced expanding human relationships because they saw different aspects of their colleagues through team-based simulation learning. This experience was also seen in other studies ${ }^{26}$ comparing the effectiveness of learning by evaluating colleagues through interactions with other students or by comparing performance among groups while watching videos together in debriefing. Some studies have shown that they have shared their opinions through the formation of positive relationships with teammates, knew there might be differences in their thoughts, and that the formation of new relationships has been of interest similar results to this study. ${ }^{25}$

Similar results were also shown in this study, as they said they experienced critical thinking through simulation learning and that other studies had an opportunity to improve their clinical reasoning ability. ${ }^{26}$

It was said that one can experience increased confidence depending on the situation, but in another study, ${ }^{26}$ he experienced improved ability to cope with emergencies. In the process of solving the problem in the scenario situation, nursing students had confidence in their actions while talking with colleagues to find the best answer, and in the process of setting up nursing plans, and transferring nursing performance, they experienced positive results, showing similar results to this study.

The factors affecting the clinical performance of nursing students were reported as clinical practice satisfaction, critical thinking, professional behaviour, communication skills, theoretical education satisfaction, etc. ${ }^{7}$ and the nursing education institution said that critical thinking, skilled nursing skills, communication skills, nursing knowledge, and universal nursing skills should be included in the practice of nursing professionals ${ }^{8}$ to be able to perform nursing care with 
the ability expected from nursing students after graduation. ${ }^{9}$ In this study results, knowledge deficiencies, relationships, critical thinking, and confidence were derived, including all the factors mentioned in the asthma simulation team learning experience prior study.

Also, the nursing student's last clinical practice experience was confirmed by nursing students to be aware of weak human beings, to be aware of nurses' responsibilities, to evaluate themselves, to look at themselves from the perspective of patients and their families, ${ }^{10}$ to think of topics such as 'difficult to relate to patients or carers', 'feeling that diverse and vivid knowledge is being accumulated', 'to do better' and 'career' 11 ' The above preceding studies were similar to those of this study.

\section{CONCLUSION}

In this study, the asthma simulation team learning experience has also been developed to have clinical practice experience and to have critical thinking by accumulating knowledge. And during the experience, I felt the difficulty of human relations while communicating with colleagues or patients. These experiences showed that the asthma simulation team learning experience was an opportunity to reflect and reflect on themselves.

These factors are also thought to be necessary for asthma simulation team learning experience training.

In the ideal, it is judged that the team is engaged in clinical practice with the process of expanding the thinking and human relationships, and self-examination, while engaging in the learning experience of the team for simulation of asthma patients.

Acknowledgement: Authors acknowledge the immense help received from the scholars whose articles are cited and included in references of this manuscript. The authors are also grateful to authors / editors / publishers of all those articles, journals and books from where the literature for this article has been reviewed and discussed.

\section{Conflict of Interest: Nil}

Source of Funding: Nil

\section{REFERENCES}

1. Yoon MO, Ju YS. The effects of peer mentoring learnings-based preclinical OSCE program on self-confidence on core basic nursing skills and critical thinking disposition for nursing student. Journal of Digital Convergence. 2017;15(7):285-95.

2. Park JS, Choi MJ, Jang SY. The effects of preclinical clinical performance examination on nursing students' confidence in nursing skills and critical thinking competence. The Journal of
Korean Academic Society of Nursing Education. 2015;21(1):7585.

3. Harden RM. Looking back to the future: a message for a new generation of medical educators. Medical education. 2011 Aug;45(8):777-84.

4. Bremner MN, Aduddell K, Bennett DN, VanGeest JB. The use of human patient simulators: Best practices with novice nursing students. Nurse Educator. 2006 Jul 1;31(4):170-4.

5. Cho MH, Kwon IS. A study on the clinical practice experiences on nursing activities of nursing students. The Journal of Korean academic society of nursing education. 2007;13(2):143-54.

6. Song J, Kim M. Study on clinical education for nursing in hospitals in Korea. The Journal of Korean academic society of nursing education. 2013;19(2):251-64.

7. Garrett B, MacPhee M, Jackson C. High-fidelity patient simulation: Considerations for effective learning. Nursing Education Perspectives. 2010 Sep 1;31(5):309-13.

8. Jocelyne Granger IA, Trudy Hebb IA, Rolanda Lavallée IA, IA MM. Team training simulation in perioperative nursing education. ORNAC Journal. 2011 Jun 1;29(2):6.

9. Halstead JA, Phillips JM, Koller A, Hardin K, Porter ML, Dwyer JS. Preparing nurse educators to use simulation technology: A consortium model for practice and education. The Journal of Continuing Education in Nursing. 2011 Nov 1;42(11):496-502.

10. Park HK. Medical education using standardized patients. Hanyang Medical Reviews. 2012 Feb 1;32(1):35-44.

11. Kneebone RL, Bello F, Nestel D, Yadollahi F, Darzi A. Training and assessment of procedural skills in context using an Integrated Procedural Performance Instrument (IPPI). InMMVR 2007 Jan 18 (pp. 229-231).

12. Eom MR, Kim HS, Kim EK, Seong K. Effects of Teaching Method using Standardized Patients on Nursing Competence in Subcutaneous Injection, Self-Directed Learning Readiness, and Problem Solving Ability. Journal of Korean Academy of Nursing. 2010 Apr 1;40(2).

13. Lewis DY, Ciak AD. The Impact of a Simulation Lab Experience for Nursing Students. Nursing education perspectives. 2011 Jul 1;32(4):256-8.

14. Kneebone R. Simulation in surgical training: educational issues and practical implications. Medical education. 2003 Mar;37(3):267-77.

15. Morrison AM, Borden CW. Your patient with COPD has arrived: Comparison of pretest and posttest scores to evaluate the effectiveness of a healthcare simulation exercise. 17th International Nursing Research Congress Focusing on Evidence-Based Practice 2006 (pp. 19-22).

16. Kim HR, Choi EY, Kang HY. Simulation module development and team competency evaluation. Journal of Korean Academy of Fundamentals of Nursing. 2011 Aug 1;18(3):392.

17. Frengley RW, Weller JM, Torrie J, Dzendrowskyj P, Yee B, Paul AM, Shulruf B, Henderson KM. The effect of a simulation-based training intervention on the performance of established critical care unit teams. Critical care medicine. $2011 \mathrm{Dec}$ 1;39(12):2605-11.

18. Koles PG, Stolfi A, Borges NJ, Nelson S, Parmelee DX. The impact of team-based learning on medical students' academic performance. Academic Medicine. 2010 Nov 1;85(11):1739-45.

19. Harder BN. Use of simulation in teaching and learning in health sciences: A systematic review. Journal of Nursing Education. 2010 Jan 1;49(1):23-8.

20. Nahas VL, Yam BM. Hong Kong nursing students' perceptions of effective clinical teachers. Journal of Nursing Education. 2001 May 1;40(5):233-7. 
21. Park JW, Ha NS. Nursing students' Clinical Experiences. Journal of Korean psychiatric and mental health nursing academic society. 2003;12(1):27-35.

22. Kang HW, Hur HK. Development of a simulation scenario on emergency nursing care of dyspnea patients. Journal of Korean critical care nursing. 2010 Dec 31;3(2):61-76.

23. Cant RP, Cooper SJ. Simulation-based learning in nurse education: a systematic review. Journal of advanced nursing. 2010 Jan;66(1):3-15.

24. Lasater K. High-fidelity simulation and the development of clinical judgment: Students' experiences. Journal of Nursing Education. 2007 Jun 1;46(6):269-76.
25. Kang HY, Choi EY, Kim HR. Nursing student's experiences in team-based simulation learning. The Journal of Korean academic society of nursing education. 2013;19(1):5-15.

26. Lee JH, Kim SS, Yeo KS, Cho SJ, Kim HL. Experiences among undergraduate nursing students on high-fidelity simulation education: A focus group study. The Journal of Korean academic society of nursing education. 2009;15(2):183-93.

27. Younsook Ju, MuyeongSeak Yang. Asthma Simulated Patient Simulation Team Learning Experience Using Hybrid Model Method. International Journal of Advanced Nursing Education and Research. 2020 Aug;5(2). 